\title{
1. Ecological modernization: theory and the policy process
}

\section{INTRODUCTION}

Ecological modernization (EM) arose in the early 1980s as a theoretical approach to describing the relationship between economics and innovation, the interventions of the nation-state and the involvement of NSAs in decision-making in order to achieve desired environmental outcomes (Mol and Sonnenfeld, 2000). Some theorists also advocate ecological consciousness as a required element in the EM model, a shift from the implied to the explicit influence over the achievement of outcomes (Howes et al., 2010; Sonnenfeld, 2000; Pellow et al., 2000).

EM is increasingly used in environmental policy analysis (Christoff, 1996; Spaargaren et al., 2009, Howes et al., 2010) because it provides an appropriate framework to explore the roles of actors in society in the process towards achieving best practice environmental outcomes. This book explores whether the public policy process, as framed by EM, should make reference to the employment and workplace impacts of climate change policy and the interventions of employers' organizations and trade unions, notably in climate change-related policymaking.

EM emerges from the social and political sciences and has established its credentials in the environmental policy field, shaping the discourse of environmental politics (Cohen, 1997). Howes et al. (2010) observe that since the 1990s there have been three theoretical approaches that have provided frameworks within the field of environmental politics: administrative rationalism, economic rationalism (neoliberalism) and ecological modernization. They find that ecological modernization as a theoretical avenue has strong relevance to environmental planning and management in many industrialized countries and as such provides a suitable framework within which to explore policy processes.

Much of the discussion concerning EM has been theoretical in nature. In Frederick Buttel's (2000) examination of the ascendance of EM as an influence over environmental policy, he refers to it as a 'well-developed and highly-codified social theory' (p. 58) pertaining to politics and the state. Maurie Cohen (1997) argues that the two major social theories shaping the 
discourse of environmental politics are Ulrich Beck's (1992) risk society theory and EM. Lange and Garrelts (2007), exploring how risk is introduced into public policy contend that EM is the most effective theoretical approach for solving environmental policy problems. Hampton (2015) and Hayden (2014) discuss EM in terms of its practical application. For Hampton, EM can be used to frame climate change policy quite precisely. Hayden likewise supports EM as an environmental policy approach, which he further links to green growth (Hayden, 2014, p. 5). Both emphasize the role of civil society and labour activists and challenge the relevance of business as usual as a policy option for the contemporary era.

EM theorists acknowledge that research is still required to embed the EM approach in different economic, cultural and political situations (Spaargaren et al., 2009). They also recognize that EM is yet to firmly establish its utility beyond developed economies. Marsden et al. (2011) find that EM has been successfully applied to the development of environmental policy in some regions in China and analysis suggests the results could be broadly replicated in other regions. The work of Sonnenfeld and Mol (2006) in 11 market-oriented industrialized and industrializing states in Asia also finds positive indications of the relevance of EM, although more research is required to confirm its priority over other theoretical frameworks. Partly in response to finding reasons for different EM manifestations in different countries and policy settings, theorists have sought to identify 'weak' and 'strong' types of EM (see for example Christoff, 1996). On this view, 'weak' models of EM might be found in developing states, such as India and Kenya. Although, as discussed below, it is only a partially valid conception of EM, some credence is found for this typology. In the lead-up to the 2015 Paris COP, for example, the governments of both countries submitted qualified INDCs whereby achievement of the targeted outcome of keeping global temperatures within 1.5-2 degrees centigrade of pre-industrial levels was conditional on the provision of significant financial support and technology from sources external to the country, since the institutions of the state are fragile and priorities are oriented more towards economic development and poverty eradication than emissions reduction per se. Both countries are vulnerable to the effects of climate change and, while EM helps identify the possible shortcomings of the proposed policy, to a large extent it is beyond the capacities of the governments and NSAs to pursue a path of 'strong' EM. Conceptions of EM such as these represent one of several ways of classifying EM, which has gone through several stages of theoretical development. The evolution of EM is shown in Figure 1.1. 


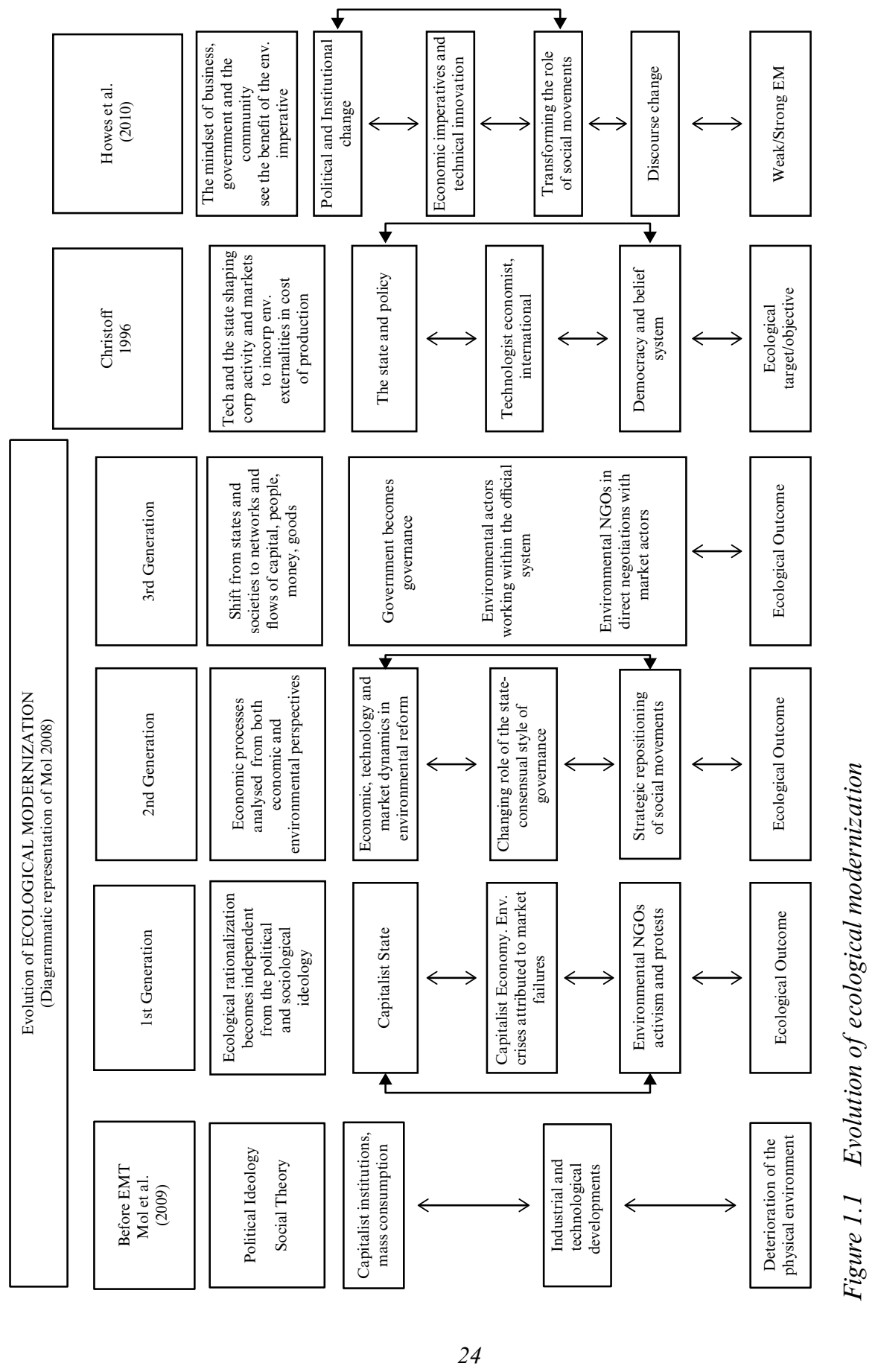




\section{Investment, Innovation and the Interventions of the Nation-state}

EM contends that the relationship between economic activity and innovation in technology and the interventions of the nation-state and civil society are required to achieve best practice environmental outcomes. Joseph Huber (1991) emphasizes the role of the state in EM, advocating that the legal foundations of environmental policy and regulation by authorities are absolutely indispensable and provide the stability factor necessary for business decisionmaking processes to innovate. He contends that the nation-state is the essential counterbalance to the unfettered behaviour of the market and its role as an active regulator is fundamental to effective environmental policy. Huber's (1991) views are supported by, among others, Hajer (1995), Sonnenfeld (2000) and Cohen (1997). However, the nation-state and industry are not mutually exclusive and it is argued by Ashford (2002) that the optimum situation is one where the nation-state provides clear standards and policy goals while allowing flexible means for industry to achieve its goals.

While articulated in different ways by theorists, there is a consistent thread that binds the contribution of enterprise with strict monitoring of performance by the state. Stern (2007) contends that effective climate change adaptation may require governments to address specific market failures and barriers. Esty and Porter (2005) concur, observing that the market on its own would not implement the strategies necessary to deliver environmental outcomes without a regulatory push. They find that environmental results are not merely a function of economic development but also a consequence of policy choices. They conclude from their research that, amongst other things, regulatory stringency and regulatory structure are highly significant in the achievement of environmental outcomes. These observations deviate significantly from Porter's earlier (1990) views, in which he contends that experimentation by the nation-state with policies to promote national competitiveness 'usually ends up only undermining it' (p. 73) and, by inference, that industry left to its own devices will deliver a competitive economy. Porter later observed that the market 'makes a false assumption about competitive reality - namely, that all profitable opportunities for innovation have already been discovered, that all managers have perfect information about them, and that organizational incentives are aligned with innovating' (quoted in Porter and van der Linde, 1995, p. 127). Stern (2007) makes a similar observation, that in the absence of public policy there are limited or no returns to private investors for [serving the public good]' (p. 27). Such contentions indicate a belief that the market on its own will not make the decisions to invest and innovate to develop the technologies necessary to meet the challenge of reducing GHG emissions. They also acknowledge that regulation on its own does not inspire 
investment and innovation. The progress towards specified ecological outcomes relies on a cooperative and mutually beneficial relationship between the nation-state with actors in the economy and investors in innovation.

\section{Civil Society}

The activists in the EM process are variously described as non-governmental organizations (NGOs) and civil society. This difference in terminology can be best understood by drawing a distinction between actors and their respective roles, a distinction that is discussed more fully in the following chapter. To recap, civil society is the collective term for civil society organizations (CSOs) and is defined as 'the wide array of non-governmental and not-for-profit organizations that have a presence in public life, expressing the interests and values of their members or others based on ethical, cultural, political, scientific, religious or philanthropic considerations' (World Bank, 2013, p. 1). 'Non-state actor' is a term used to refer to non-governmental organizations, which may be civil society organizations, transnational corporations and intergovernmental organizations (Weiss et al., 2013; Joey, 2015).

When EM theorists refer to civil society, they are alluding to environmental activists. In his discussion of EM theory, Mol (2008) uses the terms NSAs and NGOs as descriptors of activists and institutionalized players such as Greenpeace, Friends of the Earth, the World Wide Fund for Nature and the 'anti-globalisation movement' (p. 199). Although Mol does not use the term 'civil society', the groups he identifies are united by their environmental activism. Gonzales (2009) similarly infers that civil society means activists, explaining that civil society is a 'more democratic venue than the state because it is relatively unconstrained' (p. 211) and that as civil society the actors are not subordinated to state policy. Dryzek et al. (2009) offer a more expansive and inclusive role, discussing the interaction among a broad array of political, economic and social institutions resisting subordination of ecology to economics.

While scholars may generally speak of civil society as consisting largely of environmentalists, activism on environmental and climate issues in civil society has a wider scope in practice. UNFCCC has given formal recognition to more than 1,300 civil society organizations, including business and industry, environmental groups, farming and agriculture, indigenous populations, local governments and municipal authorities, research and academic institutes, labour unions and women, gender and youth groups (UNFCCC, 2011a). In its own wisdom UNFCCC refers to these all as NGOs and a whole series of related acronyms have arisen, of note to this study being BINGOs (business and industry), TUNGOs (trade unions), as well as environmental NGOs (ENGOs) (UNFCCC, 2011a). Golmohammadi (2012) 
conceives of civil society as a collective, referring to the United Nations Major Groups as their representative organizations. He proposes a management model for their collective representation as similar to the ILO, in which governments and the elected business and worker representatives have equal rights and equal representation. In the EU system, civil society is understood in the broader context and is afforded a statutory role in the formal policy process. Article 300 of the Treaty that forms the EU provides that 'the European Parliament, the Council and the Commission shall be assisted by an economic and social committee (EESC) exercising an advisory function and ... shall consist of representatives of organisations of employers, of the employed and of other parties' representative of civil society' (European Union, 2010, Art. 300). The Treaty states that the institutions of the EU must consult with the EESC on matters that include the environment and climate change (Europa, 2012b).

Earlier in the emergence of EM as an accepted theoretical framework in environmental policy analysis, it was said that 'little is known still on how, to what extent and how successfully environmental interests are included in all kind of economic, cultural and political practices' (Spaargaren et al., 2009, p.511). More recently, international agreements (2012 Rio + 20 Summit; the subsequent COPs and most recently the 2015 UNFCCC climate treaty known as the Paris Agreement) have embraced the potential of civil society, aware of the need to harness every opportunity to reduce GHG emissions. That said, national and international policy processes remain confused in the conceptions of civil society, which can have a negative impact on its ability to participate in policymaking. On the eve of the 2015 Paris COP and in the wake of the fatal terrorist attacks that occurred on 13 November that year, civic authorities placed a ban on civil society marches and protest actions. Although this ban was later lifted it had a chilling effect on non-state participation in the climate talks. This action also confused a range of civil society protagonists one with another (anti-capitalist activists with advocates for increased climate action), and also conflated proponents of non-violent direct action with actors explicitly outside civil society, such as anarchists (Cadman, 2015).

\section{The International Influence}

A series of events focused on global approaches to the sustainable development, such as the Brundtland Commission of 1987 (WCED, 1987) and the Rio Summit of 1992 (UNCED, 1992) as well as the wave of environmental events that followed created the expectation of collective international action concerning climate change. However, although the scope of these events was global, they are outcomes to which the Parties (the 
governments) have committed and accordingly also had significant influence over domestic environmental policy. In this regard, Spaargaren et al. (2009) warned of the potential conflict between international and domestic institutions, observing that the division of tasks may cut across the institutions of the state, market and civil society by mandating the sharing - and possible delegation - of responsibilities to international institutions.

Few would argue the validity of the concerns expressed by Spaargaren et al. (2009), yet in practice there are signs the model established to deliver the commitments under international agreements is failing and that domestic stakeholders feel disenfranchised. The UNFCCC management of the 2009 COP 15 in Copenhagen was criticized because it could not facilitate civil society participation in the dialogue and diminished the opportunity to civil society for access to officials (Fisher, 2010). This, with the inability of the subsequent COPs to agree to increased action to mitigate climate change or commit to the next generation of international climate agreements, has seen the focus of civil society action shifting away from such international events. Eastwood (2011, p. 35) observes that 'government participants and civil society actors alike are starting to admit that, as international negotiations stall out on the global level, local actions and smaller-scale projects will be the locus of climate change mitigation and adaptation'. While there were criticisms due to the lack of progress (BusinessEurope, 2012: Ryan, 2012), civil society maintained an active presence in the process.

By 2015 the Kyoto Protocol had effectively reached its use by date (beyond certain provisions under the Doha Amendment) and Paris loomed as the final deadline for an agreement, with further extensions unlikely. The Parties were finally able, after two weeks of tense negotiations, to find the common ground necessary to deliver a framework suitable for the move to the post-Kyoto environment, based around provisions of the Lima Paris Action Agenda (UNFCCC LPAA, 2016). The Paris Agreement permits a greater degree of flexibility for nation-states in policy and programme development and outcome delivery than under the Kyoto Protocol factors that can better facilitate the necessary domestic and international coexistence and deliver the targeted ecological outcome of reducing GHG emissions and containing the rate of global warming to two degrees or less.

\section{OPERATIONALIZING ECOLOGICAL MODERNIZATION}

The importance of EM theory to climate change policy has been well established; however, as outlined previously there are still limits to its applicability. Sonnenfeld (2000) argues that before the applicability of EM 
is examined, it must first be formally defined and operationalized. While operationalizing can be deemed as simply putting EM into practice, the process of defining EM is more complicated.

There is evidence of the increasing influence of EM in policy development. Hayden (2014) observes that in 200861 per cent of voters in Canada backed parties proposing some version of an EM-type climate response and in 2011, voters favoured pro EM policies. Hampton (2015) adds that the UK Environment Secretary in 2006 appealed for trade union engagement in climate change in ecological modernist terms. However, EM is still far from operational in the sense that the process to operationalize is not standardized and agreed upon. To reiterate the Christoff (1996) analysis of EM, the competing definitions in EM are a factor that inhibit its operation and there are aspects of EM that are interpreted differently within the literature. This flaw in the EM process has left theorists open to the criticism that they have not shown that using EM as a methodological framework leads to ecological improvements or transformation or that it reduces the direct impacts on the environment. York and Rosa (2003) contend that theorists place a greater focus on the institutional transformations than the consequences of those transformations, a contention that is strengthened if the process of operationalizing the theory fails.

\section{Measuring Policy Effectiveness}

A review of the effectiveness of climate change policy measured within the framework of EM may provide a reference point from which a methodology to operationalize the framework can be developed and qualitative and quantitative research approaches can be applied. Esty and Porter, for example, identified a benefit to environmental policy analysis and developed an environmental performance index (EPI) using both qualitative and quantitative measures (Esty and Porter, 2005). This and other scales have been used to determine 'weak' and 'strong' environmental performance. Tables 1.1, 1.2, 1.3 and 1.4 present a variety of these. Collectively, 'strong' EM is portrayed as a collaborative, deliberative process, where the state provides markets and civil society actors access to all the necessary information and institutions for achieving the desired environmental outcomes. The state then regulates and acts to ensure compliance. Moderating themes across the different conceptualizations are that some 'strong' versions allow for multiple EM possibilities, while others focus more on EM's contribution to more internationally oriented outcomes. 'Weak' ecological modernization is represented as less collaborative, the state regulates to facilitate the market, the focus is national rather than international and the strategy is hegemonic rather than offering multiple opportunities. 
Table 1.1 Ecological modernization as viewed by Howes et al. (2010)

\begin{tabular}{|c|c|c|}
\hline & 'Weak' EM & 'Strong' EM \\
\hline View of the environment & Economist and utilitarian & Ecological \\
\hline Role of the state & $\begin{array}{l}\text { Market facilitation, } \\
\text { information dissemination, } \\
\text { minimum state } \\
\text { intervention }\end{array}$ & $\begin{array}{l}\text { Substantial state } \\
\text { intervention, } \\
\text { institutional } \\
\text { restructuring, reforms } \\
\text { to economic and } \\
\text { regulatory policies }\end{array}$ \\
\hline Policy approach & Instrumental & Communicative \\
\hline Decision-making style & $\begin{array}{l}\text { Technocratic/closed decision- } \\
\text { making by economic and } \\
\text { political elites }\end{array}$ & $\begin{array}{l}\text { Deliberative democratic/ } \\
\text { open, with } \\
\text { participation and } \\
\text { involvement }\end{array}$ \\
\hline Scale of focus & $\begin{array}{l}\text { National focus on developed } \\
\text { nations }\end{array}$ & International \\
\hline EM strategy & Hegemonic & $\begin{array}{l}\text { Diversifying, multiple } \\
\text { possibilities with EM } \\
\text { providing orientation }\end{array}$ \\
\hline
\end{tabular}

Source: Howes et al. (2010).

Table 1.2 Ecological modernization as viewed by Christoff (1996)

\begin{tabular}{ll}
\hline 'Weak' EM & 'Strong' EM \\
\hline Economistic & Ecological \\
Technological & Institutional/systemic \\
Instrumental & Communicative \\
Technocratic/neo-corporatist & Deliberative democratic/open \\
National & International \\
Unitary & Diversifying \\
\hline
\end{tabular}

Source: Christoff (1996).

Janicke's (2008) EM-friendly framework of environmental regulation (shown in Table 1.4) is a fair representation of the vast middle ground between these representations of 'weak' and 'strong' conceptions but has a clear leaning to 'strong' EM. Mol (2001), in his comparison of EM with the treadmill of production concept, also sits in the middle but with a leaning to the 'weaker'. 
Table 1.3 Environmental change versus economic continuity

\begin{tabular}{|c|c|c|}
\hline & Treadmill of production & Ecological modernization \\
\hline Kind of radicality & Economic radicality & Environmental radicality \\
\hline Environmental improvements & Absolute sustainability & Relative improvements \\
\hline $\begin{array}{l}\text { Assessment of environmental } \\
\text { change }\end{array}$ & Window dressing & Real changes \\
\hline $\begin{array}{l}\text { Relationship between } \\
\text { changes analysed and } \\
\text { changes proposed }\end{array}$ & Weak relation & Strong relation \\
\hline Main emphasis & Institutional continuity & $\begin{array}{l}\text { Institutional } \\
\text { transformations }\end{array}$ \\
\hline
\end{tabular}

Source: $\operatorname{Mol}(2001)$.

\section{Table 1.4 Ecological modernization and innovation-friendly framework of environmental regulation}

\begin{tabular}{|c|c|}
\hline Policy objective & Policy content \\
\hline $\begin{array}{l}\text { Instruments are EM and innovation } \\
\text { friendly if they }\end{array}$ & $\begin{array}{l}\text { Provide economic incentives } \\
\text { Act in combination } \\
\text { Are based on strategic planning and goal } \\
\text { formulation } \\
\text { Support innovation as a process and } \\
\text { take account of the different phases of } \\
\text { innovation/diffusion }\end{array}$ \\
\hline $\begin{array}{l}\text { A policy style is EM and innovation } \\
\text { friendly if it is }\end{array}$ & $\begin{array}{l}\text { Based on dialogue and consensus } \\
\text { Calculable, reliable, and has continuity } \\
\text { Decisive, proactive, and demanding } \\
\text { Open and flexible } \\
\text { Management oriented }\end{array}$ \\
\hline $\begin{array}{l}\text { A configuration of actors is EM and } \\
\text { innovation friendly if }\end{array}$ & $\begin{array}{l}\text { It favours horizontal and vertical policy } \\
\text { integration } \\
\text { The various objectives of regulation are } \\
\text { networked } \\
\text { The network between regulator and } \\
\text { regulated is a tight one } \\
\text { The relevant stakeholders are included in } \\
\text { the network }\end{array}$ \\
\hline
\end{tabular}

Source: Janicke (2008). 
While these measurement tools are appropriate as descriptive representations of policy rating options within the framework of the theory, they do not sufficiently inform the policy development process and the interventions necessary to provide certainty about the environmental outcome. The terms 'weak' and 'strong' are taken from the literature and are used here in the absence of other understood nomenclature, or a quantitative measure such as that provided in the EPI. Mol (2001) holds the view that EM is about relative improvement in environmental conditions rather than absolute sustainability. Christoff (1996) argues that 'weak' and 'strong' are measured by the choices made. Hajer (1995) speaks of EM as a discourse that recognizes the structural character of the environmental problematic and institutions can internalize the care for the environment. Howes et al. (2010) speak of a situation where ecological principles are seen by the state, market and civil society actors as the required policy goal of both institutions and business.

A discussion about measures of effectiveness should focus less on whether EM is 'weak' or 'strong', implying 'good' and 'bad' but, rather, if it is able to account for the outcomes that are expected from the policy initiatives. A policy is structured to deliver a specified result, and may yield an 'ideal' outcome, free from any constraining factors - or the outcome may be contingent, such as one determined by a nation-state's unique set of circumstances. In reality, the ideal is rarely achievable. The outcome may therefore arise from the best available (or 'optimum') set of policy choices, given contingent factors. Furthermore, given such contingencies, it is also possible that a given set of policy choices may not represent the best available set of choices, and be influenced by further factors. In this case, the outcome may be 'sub-optimum'.

For the purposes of the discussion here the outcome sought by the state is a consequence of its sustainability and climate change policies. In the EU these are based on its 2030 Climate and Energy Framework, while in the UK it is its Climate Change Act 2008 and related legislation. In the case studies that follow, the findings are analysed to determine what version of EM model they conform to, what the policy framework constitutes, and whether it represents an ideal, optimum, or sub-optimum outcome.

Climate change policy is influenced by a range of contingencies, which includes national, cultural, economic, social and political contexts. Within these parameters there are no absolute measures, that is, actions that are correct in all situations, merely what is achievable and appropriate to the circumstances. Consequently, it is suggested that while useful parameters for general assessment, the 'weak' and 'strong' terminology is not sufficiently nuanced to represent the gamut of choices, which policymakers confront, and represents a dualist classification, that does not fully align with contemporary social-political circumstances. Therefore, it is used here 
for descriptive purposes of the existing EM literature, rather than constituting a preferred typology.

\section{Operationalizing Ecological Modernization}

To implement EM and permit EM to guide policymakers requires consistency in definitions and terminology. Christoff (1996) argues that the competing definitions in EM is a factor that inhibit its operation and there are aspects of EM that are interpreted differently within the literature, some of which are noted in Table 1.2. Additionally, the application of EM is hampered by a lack of clarity about the preferred steps to guide the process of its operationalization.

The multiple descriptions of EM are a rich source of diverse opinion about its true nature. A list of some of the theorists' conceptualizations of EM is shown in Table 1.2. These conceptualizations consider EM as either a general descriptor of trends (Cohen, 2000), a discourse that recognizes the structural character of the problematic (Hajer, 1995) and a centripetal movement of ecological interests, ideas and consideration in the State's institutional design (Mol, 2008). Ashford (2002) adds the requirement for the involvement of a broad array of stakeholders. This research concludes that the varied conceptualizations of EM do not blur its usefulness, a concern expressed by Christoff (1996), but rather add to the complexity of the task of its operationalization.

Across all of the differing views of what EM is and does, each of the conceptualizations are built around the elements of innovation, the state, market, civil society and ecological consciousness. As shown in Table 1.5, the language of EM theorists provides potentially conflicting interpretations of EM and its potential to be operationalized. This leads to the understanding that if EM is to serve as a guide in the practice of policy development, it is necessary to find consistency in language and understanding. The standardized description of EM proposed for this research is the relationship between the innovation and technology, the market, interventions of the state, the role of civil society and ecological consciousness in decision-making in the pursuit of environmental outcomes.

The theorists' discussions and social theory literature do not apply the language of EM consistently and often use different terms when describing the same concepts. This creates confusion and establishes a potential barrier to the theory's operationalization. For instance, the term 'institution' is sometimes used as a reference to institutions of the state, while in other discussions it is a reference to institutions of the market. In order to address the problem created by the multiple interpretations, a 
Table 1.5 Conceptualizations of ecological modernization

\begin{tabular}{|c|c|}
\hline Theorist & Definition of EM \\
\hline Cohen (2000) & $\begin{array}{l}\text { Defines EM as a term adopted as a general descriptor } \\
\text { of trends in the application of science and } \\
\text { technology to environmental problems and the } \\
\text { efforts to reconcile conflicting objectives between } \\
\text { responsibility for the environment and continual } \\
\text { economic expansion }\end{array}$ \\
\hline Hajer (1995) & $\begin{array}{l}\text { Conceptualizes EM as the discourse that recognizes the } \\
\text { structural character of the environmental problematic } \\
\text { but nonetheless assumes that existing institutions can } \\
\text { internalize the care for the environment }\end{array}$ \\
\hline Howes et al. (2010) & $\begin{array}{l}\text { Speaks of a situation where ecological principles are seen } \\
\text { by the state, market and civil society actors as the } \\
\text { required policy goal of both institutions and business }\end{array}$ \\
\hline Janicke (2008) & $\begin{array}{l}\text { Considers EM a systematic eco-innovation and its } \\
\text { diffusion }\end{array}$ \\
\hline Langhelle (2000) & $\begin{array}{l}\text { Conceives of EM not so much a set of sociological theories } \\
\text { but rather as a political programme favouring a } \\
\text { particular set of policies }\end{array}$ \\
\hline Mol (2001) & $\begin{array}{l}\text { Contends that the notion of EM can be seen as the social } \\
\text { scientific interpretation of environmental reform } \\
\text { processes at multiple scales in the contemporary world. } \\
\text { EM studies reflect how various institutions and social } \\
\text { actors attempt to integrate environmental concerns into } \\
\text { their everyday functioning }\end{array}$ \\
\hline Mol (2008) & $\begin{array}{l}\text { States that the basic idea of EM is that at the end of the } \\
\text { second millennium, modern societies witness a } \\
\text { centripetal movement of ecological interests, ideas and } \\
\text { considerations in their institutional design }\end{array}$ \\
\hline $\begin{array}{l}\text { Mol and Sonnenfeld } \\
(2000)\end{array}$ & $\begin{array}{l}\text { Refer to EM as the relationship between economics and } \\
\text { innovation, the interventions of the nation-state and the } \\
\text { involvement of NSAs in the decision-making to achieve } \\
\text { environmental outcomes }\end{array}$ \\
\hline Simonis (1989) & $\begin{array}{l}\text { Submits EM as resolution of environmental problems } \\
\text { through harmonizing ecology and economy }\end{array}$ \\
\hline Ashford (2002) & $\begin{array}{l}\text { Tenets of the still-evolving EM theory that have been } \\
\text { melded into the following theory: } \\
\text { Unregulated capitalism is responsible for the present } \\
\text { ecological and environmental problems and this is } \\
\text { partly because the prices of goods and services do not } \\
\text { adequately represent the social cost of production and } \\
\text { consumption }\end{array}$ \\
\hline
\end{tabular}


Table 1.5 (continued)

\begin{tabular}{ll}
\hline Theorist & Definition of EM \\
\hline Under thoughtful reflexivity, the present and enlightened \\
industrial actors can succeed in advancing the material \\
wellbeing of citizens, contribute to their nation's \\
competitiveness and can also contribute to the necessary \\
scientific and technical changes (innovations) in \\
products, processes and services to adequately meet the \\
environmental challenges, especially if a broad array of \\
stakeholders is involved
\end{tabular}

standardized definition is proposed for each of the terms, while remaining true to the intent of the theorists. These definitions are discussed below.

\section{Proposed definitions}

- Innovation and technology is adopted as the standardized term to represent the intentions of the theorists when they speak of science (Cohen, 2000), science and technology (Mol and Sonnenfeld, 2000) and technological innovation (Howes et al., 2010; Ashford, 2002). The meaning adopted for this research defines innovation and technology as 'the application of new solutions and the practical application of knowledge' (Merriam-Webster, 2013).

- The state is also variously described in EM, with some authors focusing on particular attributes such as the state as the regulator, change agent and institution (Howes et al., 2010; Janicke, 2008; Dryzek et al., 2009). This research defines the state as the agent for shaping the structures and policies of the state and other national and local actors in social life including business, politics and civil society (Meyer et al., 1997).

- The market is variously described as pursuit of the economic imperative (Howes et al., 2010) and application of economic rationality (Dryzek et al., 2009). The meaning adopted for this research is the market as the area of economic activity in which buyers and sellers come together and the forces of supply and demand affect prices (Merriam Webster, 2013).

- Civil society is described in some instances quite differently (see section Defining Civil Society in Chapter 2 for a more detailed discussion). The discussion seeks to reconcile the EM theorists' 
general representations of civil society as environmental activists with the Organisation for Economic Co-operation and Development (OECD), UN and World Bank's broader considerations of civil society as a range of stakeholders and interest groups that are involved and influential over public policy. The meaning adopted for this research is civil society as the wide of array of organizations including community groups, NGOs, labour unions, indigenous groups, charitable organizations, faith-based organizations and professional associations (World Bank, 2013).

- Ecological consciousness was selected over other terms that are used in EM such as discursive change (Mol and Sonnenfeld, 2000; Howes et al., 2010), Christoff's (1996) hegemonic progress and Cohen's (2000) epistemological perspective. The meaning adopted for this research of ecological consciousness is the consideration of ecological principles in the desired policy goals of both institutions and business (Howes et al., 2010; Christoff, 1996; Cohen, 2000).

- Ecological outcome is discussed at length in the following section and introduces the concept of defined pathways to provide a more concrete guide than the range of weak to strong EM that is the language of many theorists.

The standardization of these terms removes one of the barriers to the operationalization of EM. Consequently, the process to develop policies that implement EM is provided here. This represents an ideal EM. However, such an EM type is not what is always sought by policymakers, who may prefer a template that simply allows for the monitoring and evaluation of contingent policy choices. An ideal EM framework, it is suggested, constitutes the following:

1. Orientation to EM theory. Policy objectives seek to harmonize the economy with the environment; standardized definitions to strengthen governance of EM and its components exist; application of the policy is ensured by sufficient resources and related capabilities; policy application and enforcement includes the achievement of the specified ecological outcomes;

2. Outcome selection. The desired outcome of the policy is specified these may be science based around addressing specific environmental concerns, a process-oriented model that seeks to harmonizes the economy and the environment in specific but realistic ways, or the achievement of a specified outcome such as a GHG emission reduction target;

3. Policy interventions that deliver the desired outcome. 


\section{ECOLOGICAL MODERNIZATION THEORY: THE ECOLOGICAL OUTCOME}

\section{The Pathways to the Environmental Outcome}

Outstanding from the discussion to standardize the definitions in EM is a definition of what constitutes the 'ecological outcome'. The specification of an ecological outcome will take into account whether the measure of harmonization of the economy and the environment is to be judged in the absolute or whether it is a measure of what is achievable in the particular circumstances of a country, as alluded to previously. In many countries, the outcome specification reflects the commitment by the state to international climate change agreements. In Europe the outcome specification is the EU 2030 Climate and Energy Framework (Europa, 2016) to deliver reduced emissions and energy security, which embraces the EU commitment to UNFCCC agreements.

Analysis of theorists' conceptualizations of the outcomes in the EM model led to the conclusion there is not one clear outcome but a range from the environmental imperative to that of decoupling economic growth from environmental harm. This range, commonly described as 'weak' to 'strong' EM outcomes, can be described more precisely across the range as:

- Outcome 1: harnessing science and the environment to address contemporary ecological concerns;

- Outcome 2: decoupling economic growth from environmental harm where success is measured as progress towards absolute sustainability;

- Outcome 3: decoupling economic growth from environmental harm where success is measured as progress towards a specified outcome or a target.

Table 1.6 shows the ecological outcomes aligned to these three pathways. Table 1.7 then charts the possible interventions along the pathways to deliver the outcome in the context of the components of EM.

The pathway to Outcome 1 reflects an environmental requirement to which other considerations are subordinate. The policy framework to support these objectives could involve innovation from science and technology, institutional reshaping by the state and transforming ecological consciousness through the reflexive process of social learning. Policy interventions could be waste reduction and elimination, resource recovery and reuse, with long-term objectives as resource conservation and clean production ${ }^{1}$ (Sonnenfeld, 2000; Janicke et al., 1997; Hajer, 1995; Cohen, 2000). 
The pathways to Outcomes 2 and 3 rely on a common policy framework described by Maarten Hajer (1995) as making environmental degradation calculable, environmental protection as a positive sum game and the reconciliation of economic growth with ecological systems. The policy interventions proposed by Howes et al. (2010) include technological innovation, engaging with economic imperatives, political and institutional change, transforming the role of social movements and ecological consciousness. Although the policy framework for Outcomes 2 and 3 are common, the pathways differ in their focus. The pathway for Outcome 2 has a focus on process-oriented policy, whereas the pathway for Outcome 3 addresses the policy choices to deliver the outputs required.

A range of approaches to environmental policymaking and for assessment of sustainability have been provided in research and reports by the OECD (2013a), Green Growth Knowledge Platform (GGKP) (2013) and the World Bank (2013). The GGKP has also developed a comprehensive set of diagnostic indicators that have parallel features with the EM model.

The GGKP is a global network of researchers and development experts sponsored by the Global Green Growth Institute, OECD, the United Nations Environment Programme (UNEP) and the World Bank that identify and address knowledge gaps in green growth theory and practice. The GGKP research is a model of Outcome 2 and speaks of the pathway in the five well-recognized stages of the public policy development process: agenda setting, policy formulation, decision-making, policy implementation, and monitoring and evaluation (GGKP, 2013). Policy formulation is also best guided by a process that is evidence based, which means that it has rigour, is inclusive and can be evaluated. The evidence-based approach of EM is discussed in the next section.

In EM terms, the OECD proposal is a pathway to Outcome 3. The OECD (2013a) proposes policy instruments in three categories: taxing, pricing and mechanisms that value natural assets; regulations, standards and information policies; and a set of cross-cutting policies to stimulate green growth in a systemic way. The cross-cutting policies referred to are investment, research and development; labour and skills; and climate adaptation (OECD, 2013a; 2013b). It reports that progress along the pathway to achieve a chosen outcome requires commitment to a vision and plan for green growth. The process to achieve the outcome involves the design, reform and implementation of policies that stimulate green growth, and strengthen governance - including capacity building for sound decisionmaking to monitor and enforce policies.

Two points in the OECD (2013a) approach merit comment here. First, labour and skills are important issues to be included in both short and 
long-term climate change planning; second, targets are beneficial in climate change planning but if there are too many there is the potential for conflicting policy, a consideration the UK has not factored into its climate change strategies. The UK has set itself many targets, making commitments to international and EU agreements and its own further targets. An OECD (2010) review of UK climate change policies added that more could be done to align the economic and environmental objectives and the integration of programmes across portfolios. Additionally, monitoring of climate policy effectiveness by the UK government's Committee on Climate Change has found that some programmes are at the limits of their capacity and that step change is required in the suite of policies if all of the set targets are to be met (DECC, 2011e). The OECD and ILO reviews of the UK labour market and skill development finds the policies are weak and the anticipated shortage of labour and skills will create barriers to service delivery (Miranda and Larcombe, 2012; Strietska-Ilina et al., 2011; Gleeson et al., 2011).

The finding that there is not one single scenario to be considered in the operationalization of EM but a range is critical, as it is only by committing to an outcome that the state can make the effective policy interventions that will lead to the required environmental outcome. The choice of outcome will dictate whether policy requires a strong science orientation, whether policies will be seeking to deliver progress towards absolute sustainability or whether they deliver a target such as specified volume of GHG emissions reduction.

Table 1.6 Theorists' objective for ecological modernization

\begin{tabular}{lccc}
\hline & Outcome 1 & Outcome 2 & Outcome 3 \\
\hline Huber (1991) & $\mathrm{x}$ & $\mathrm{X}$ & \\
Hajer (1995) & $\mathrm{x}$ & $\mathrm{X}$ & \\
Christoff (1996) & & $\mathrm{x})$ & \\
Cohen (1997) & & $\mathrm{x}$ \\
Jokinen (2000) & $(\mathrm{x})$ & & $\mathrm{x}$ \\
Pellow et al. (2000) & & $\mathrm{x}$ & $\mathrm{x}$ \\
Sonnenfeld (2000) & & $\mathrm{X}$ & \\
Mol (2001) & & $\mathrm{x}$ & \\
Janicke (2008) & & \\
Howes et al. (2010) & &
\end{tabular}

Note: (X) Primary influence over the outcome; (x) Secondary to the primary influence over the outcome. 
Table 1.7 Scenarios for the achievement of ecological modernization

\begin{tabular}{lcccc}
\hline Pathways & & Outcome 1 & Outcome 2 & Outcome 3 \\
\hline Innovation and technology & $\mathrm{a}$ & $\mathrm{x}$ & $\mathrm{x}$ & $\mathrm{x}$ \\
& $\mathrm{b}$ & $\mathrm{x}$ & $\mathrm{x}$ & $\mathrm{x}$ \\
State & $\mathrm{a}$ & & $\mathrm{x}$ & \\
Market & $\mathrm{b}$ & & $\mathrm{x}$ \\
Civil society & $\mathrm{a}$ & & $\mathrm{x}$ \\
& $\mathrm{b}$ & $\mathrm{x}$ & $\mathrm{x}$ & \\
& $\mathrm{a}$ & & $\mathrm{x}$ \\
Ecological consciousness & $\mathrm{b}$ Other & $\mathrm{x}$ & \\
& $\mathrm{b}$ & $\mathrm{x}$ & $\mathrm{x}$ & \\
\hline
\end{tabular}

Note: $\mathrm{a}$ and $\mathrm{b}$ : Indicates the relative priority where $\mathrm{b}$ is the higher priority; ${ }^{*}$ Other and Environ draw a distinction between other civil society organizations and environmental activists.

\section{Evidence-based Policy}

This section presents an approach to public policy development within an EM framework that is based on evidence and processes that have rigour. The GGKP (2013) contends that green growth and green economy policies need solid evidence-based foundations. EM introduces policy considerations that are not necessarily informed by hard physical data but are qualitative by nature, such as the role of civil society, or the value to policy implementation that is supported by the community.

Evidence-based policy (EBP) is public policy informed by rigorously established objective evidence (Head, 2010). While it is not the only process for developing policy, it is a process that demonstrates evidence from qualitative study can be accepted as objective provided that it is collected in a manner that has discipline and where the outcomes can be measured. While an EBP approach is traditionally based on quantitative methods and statistical techniques and analyses, the value of qualitative evidence has been widely debated in the EBP community in recent years (Smith, 1996). The World Health Organization (WHO) has developed guidelines using evidence-based approaches that rely on qualitative data gathered from existing research, input from multidisciplinary experts, and peer-review (WHO, 2011). In the UK, the Cabinet Office maintains that evidence for the purposes of informing policy includes the management of academic research and professional and/or institutional experience (Parsons, 2002). 
There are three enabling factors that underpin modern conceptualizations of EBP: high-quality information based on relevant topic areas, cohorts of professionals with skills in data analysis and policy evaluation and political incentives for utilizing evidence-based analysis and advice in decision-making processes. Western countries have developed a strong institutional foundation for nurturing EBP capacities. Their commitment to good data and sound analysis has been reinforced by their involvement in international organizations such as the OECD and their endorsement of international agreements that require sophisticated reporting.

However, while the institutional capacity necessary to support EBP has increased, public policy development in the Western countries is still often based on guesswork and assumptions rather than as a process in which the social policy or sciences have an influential part to play (Parsons, 2002; Hayes, 2007). In the UK in 1997, the newly elected Labour government sought to address that situation and in its White Paper Modernizing Government declared its intention to introduce evidence-informed processes in order to provide better-informed development and delivery of government policy (UK Government, 1999). To ensure the requirements of the White Paper would not stall for lack of appropriate capabilities within the public service, the government provided for access to skills, experience and domain knowledge developed outside the government that could be used to improve the quality of policy discourse within government departments (Levitt and Solesbury, 2005). Interestingly, it was not monitored or evaluated following the Paper's release, and leads to questions of whether in fact it is being effectively implemented, a reasonable question when the government's Committee on Climate Change reports evidence of resistance to adoption of climate change policies within the public sector (DECC, 2011f).

In EM, theorists have traditionally been more concerned with developing the conceptual and policy implications of their framework and less with evidence-based analysis. If EM is to be relevant and used as a guide in the development of contemporary policy, the pathways to the chosen outcome must provide for an evidence-based policy selection.

\section{Monitoring and Evaluation}

The monitoring and evaluation phase of policy development and implementation is essential for assessing the need for policies and whether they achieve their stated goals. The evaluative criteria developed by Guyatt et al. (2008) rates the quality of the evidence on a scale of between high, moderate, low and very low quality. WHO's (2011) 
policy indicator and guideline development process commences with the formation of a Guidelines Review Committee to undertake a scoping (including a review of existing guidelines and selection of the critical outcomes and draft key questions); the formation of, and consultation with, an expert panel; implementation of a step-by-step methodology; meeting of the global panel of experts; final guidelines report; clearance by the Guidelines Review Committee; and finally, publication and dissemination.

The Kyoto Protocol introduced a platform for a monitoring, evaluation and reporting regime, which was a significant achievement and an important requirement in effective public policy (UNFCCC, 1997). The Paris Agreement as a 'next generation' treaty builds on this base to implement a comprehensive programme that is aimed at ensuring transparency of action and support, as well as facilitating the reporting of progress towards achieving targets in a timely manner - and undertaking appropriate remedial action if they are not (UNFCCC, 2015, paragraphs 85-105). To that end, an EM model must also accommodate these requirements.

\section{ECOLOGICAL MODERNIZATION AS A GUIDE TO POLICY CHOICES}

Can an operationalized EM guide the policy development process and the policy choices? The negotiation of international agreements is a complex and lengthy process that demonstrates the commitment of the states to the environment and in particular to addressing climate change, a commitment that it is expected will guide national approaches to domestic policy development. Agreements are not currently framed by theoretical models and an operationalized EM might well serve international and domestic policy development processes as they adapt to the economic and social changes necessary to reduce GHG emissions. But it also needs to be recognized that each nation-state has unique political, economic, social and cultural sensitivities that influence policy choices, and these may be constraining factors over implementation of 'stronger' versions of EM; as required to achieve the optimum EM outcome for the given context.

The agreements from the Rio +20 Conference (UNCSD, 2012a) and the UNFCCC COPs influence the decisions of the state and the policy choices for climate change adaptation and mitigation strategies. To establish if there were indications that there may be gaps between the EM framework, UNFCCC agreements and domestic climate change policy, the EM template presented in this volume was overlaid on a sample of countries 
notable for their contribution to global climate change management efforts as well as being high GHG emitting countries.

Table 1.8 is a diagrammatic representation of the findings from this test.

While EM theorists generally speak of EM on a scale of weak to strong, it was considered that policymakers would be better assisted by a more definitive measure. To that end and with consideration of the Pathways to operationalize EM, measures of low, medium and high were adopted in place of the weak to strong scale, and the values of 0,5 , and 10 were applied to low, medium and high (weak to strong) models of EM. In some instances, the policy options were conditional, for example in the UK the commitments by the state are ambitious and are supported by a suite of programmes intended to deliver the targeted outcomes and are accordingly are afforded a high (10) rating. However, the government's Committee on Climate Change had submitted to the government that many of the programmes are at their capacity and must be scaled up if targets are to be met. The government to date not acted on this recommendation, a situation that it is considered must be reflected in the valuation as a negative rating $(-10)$, providing range in the model to guide policymakers.

The spread in the scores is indicative of the diversity of the situations, which are in each case framed by policy designed to achieve the expressed outcomes. For the UNFCCC, the outcome of containing global warming to less than 2 degrees while also facilitating social development and economic growth significantly influence the policy options and is the reason for a high spread in the scores. The EU and UK introduced an energy security mandate, and China and India are still pursuing a development agenda. In the scoring of the respective agreements and policies, the EU performance was strengthened by the effective implementation of policy by its member states, as demonstrated in the case of the UK. UNFCCC performed relatively well in terms of achieving its desired outcome. All three demonstrate a solid performance. China and India did not achieve their optimum EM outcome. Of note in all these results is the role extended (or withheld) from civil society actors. In EM, civil society is integral to the achievement of the ecological outcome.

Overlaying the EM template on the chosen sample identified where the agreements and policies diverge from the EM model. For example, the UNFCCC seeks to achieve the multiple objectives of containing global warming, promoting economic growth and social development; the EU and UK have added energy security as an imperative, and in India and China the institutions of the state, market and civil society are weak. Until the 2015 Paris COP, the UNFCCC agreements also exempted some of the world's major GHG emitters (China, India, Brazil and Indonesia) from legally binding commitments to reduce 


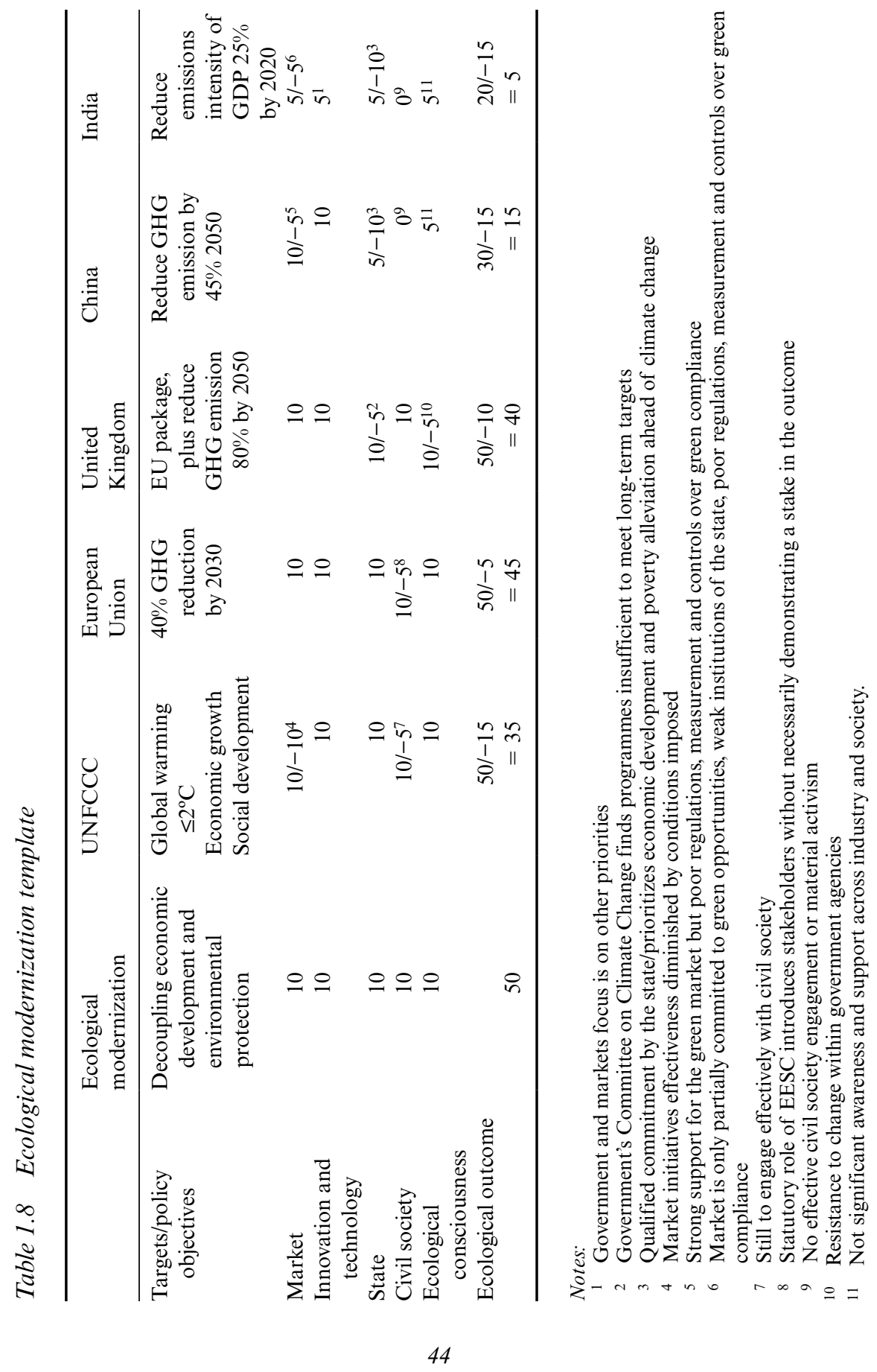


GHG emissions through the common but differentiated responsibilities (CBDR) provisions.

This experiment is illuminating in that it draws attention to the direct links between the defined objectives and the outcomes. In the instance of EM, the objective is the decoupling of economic development and environmental protection whereas the UNFCCC seeks the containment of global warming, economic growth and social development, and the EU and UK add energy security. Accordingly, the expectations of the contribution of the theoretical framework can only be to that common aspect of the defined objectives.

\section{CONCLUSION}

The theoretical framework presented here has provided a set of conditions to contextualize the application of EM in practical policy contexts. To that end, and as established in the exercise, an operationalized EM serves to identify where there are gaps in the suite of policies and programmes, that may inhibit the ability to achieve the desired ecological outcome, recognizing there may be other factors that could also create such a barrier, but are outside the scope of the theoretical framework.

UNFCCC's Kyoto Protocol and the INDCs under the 2015 Paris Agreement provide for ratifying nations to commit to specific targets and timeframes concerning emission reductions and many member states, particularly in developed economies, have framed domestic policies with these targets as outcomes. While the international agreement and the domestic policies examined in the experiment can be described as models of optimum EM, the multiple objectives of those agreements and policies may mitigate against and complicate progress towards the achievement of the desired ecological outcome. In the cases of India and China, the constraints imposed on climate policy delivered a sub-optimum result. Consequently, it is worth recognizing that there is tension between 'achieving the achievable' in environmental policy, and subordinating the required ecological outcomes to external policy imperatives. The requirement that international agreements and regional/national level implementation of climate policies should facilitate economic growth overlooks concerns about the finite nature of available resources, and subverts the requirement to change methods of production and consumption. The principle of common but differentiated responsibilities, while honourable and possibly even appropriate in 1992 when the Convention was adopted, provided an exemption for countries that are now major economies as well as the largest GHG emitters. The Paris Agreement has partially 
addressed this historical legacy, but CBDR may well continue to cast a shadow over the implementation of optimum EM models for developing countries.

\section{NOTE}

1. Clean production is production without (unrecycled) waste or emissions (Janicke et al., 1997). 